\title{
Impact of Food Disinfection on Beneficial Biothiol Contents in Vegetables
}

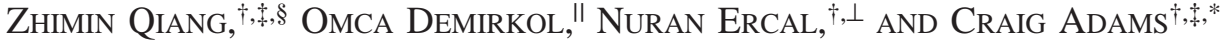 \\ Environmental Research Center for Emerging Contaminants and Departments of Civil, Architectural \& \\ Environmental Engineering and of Chemistry University of Missouri-Rolla, Rolla, Missouri 65409, \\ State Key Laboratory of Environmental Aquatic Chemistry, Research Center for Eco-Environmental \\ Sciences, Chinese Academy of Sciences, Beijing 100085, China, and Department of Food \\ Engineering, Sakarya University, Sakarya 54187, Turkey
}

\begin{abstract}
In this work we investigated the impact of food disinfection on the beneficial biothiol contents in a suite of vegetables consumed daily, including spinach, green bean, asparagus, cucumber, and red pepper. Four disinfection technologies commonly studied and/or used in food processing and preservation, including hydrogen peroxide, free chlorine, and gaseous- and aqueous-phase ozone, were examined with common dosages and contact times. Results indicate that the common disinfection technologies may result in significant loss of beneficial biothiols in vegetables which are essentially important to human health. For example, as much as $70 \%$ of biothiols were lost when spinach was treated with hydrogen peroxide (5.0 wt \%) for $30 \mathrm{~min}$. Approximately $48-54 \%$ of biothiols were destroyed by free chlorine and gaseous- and aqueous-phase ozone under typical contacting conditions. In red pepper, about $60-71 \%$ of reduced glutathione was oxidized by the disinfectants. The potential decrease in biothiols during disinfection was dependent upon the biothiol type, the disinfectant, and the vegetable. The effectiveness of total bacterial inactivation by the four disinfection technologies was concurrently evaluated. Results show that free chlorine is most effective, achieving disinfection efficiencies of greater than $4 \mathrm{log}$ for all study vegetables. This study may provide important information for the food industry to design optimum contacting methods for vegetables to simultaneously achieve sufficient bacterial disinfection while minimizing loss of beneficial biothiols.
\end{abstract}

KEYWORDS: Biothiol; antioxidant; chlorine; hydrogen peroxide; ozone; disinfection; vegetable

\section{INTRODUCTION}

Numerous outbreaks of food-borne diseases have been reported in recent years $(1-4)$, which make disinfection desirable in processing and preserving various foods including vegetables, fruits, meats, and poultry. Disinfection is a process designed for selective inactivation or destruction of pathogenic organisms (i.e., viruses, bacteria, and protozoa) to protect public health as well as for control of fungi to extend shelf life. The disinfectants commonly studied and/or used in the food industry include ozone (either gaseous- or aqueous-phase), free chlorine $\left(\mathrm{HOCl} / \mathrm{OCl}^{-}\right)$, and hydrogen peroxide.

Ozone has recently been approved as an antimicrobial agent on food by the U.S. government (21 CFR Part 173.368) (5). Disinfection using ozone occurs by direct physical contact

* To whom correspondence should be addressed. Phone: (573) 3414041. Fax: (573) 341-7217. E-mail: adams@umr.edu.

Environmental Research Center for Emerging Contaminants, University of Missouri-Rolla.

$\doteqdot$ Department of Civil, Architectural \& Environmental Engineering, University of Missouri-Rolla.

$\S$ Chinese Academy of Sciences.

"Sakarya University.

$\perp$ Department of Chemistry, University of Missouri-Rolla. between microorganisms and the ozone gas stream or by action of dissolved ozone and its products (i.e., hydroxyl radicals generated by aqueous ozone at high $\mathrm{pH}$ ). The characteristics of strong reactivity, high penetrability, and spontaneous decomposition to nontoxic oxygen gas make ozone attractive for use as a viable disinfectant in food processing $(6-8)$. Ozone, either gaseous- or aqueous-phase, has been widely studied to inactivate pathogenic bacteria (e.g., Salmonella species, Escherichia coli O157:H7, and Listeria monocytogenes) for lettuce (9), whole black peppercorn and ground black pepper (10), apple cider and orange juice (11), apples, strawberries, and cantaloupe $(12,13)$, cucumbers (14), cabbage $(15)$, and beef $(16,17)$, as well as control fungi to extend the shelf life of various fresh fruits (18).

Free chlorine can be applied as a disinfectant in three forms: as a pressurized gas, as hypochlorous acid, or as hypochlorite. Sodium or calcium hypochlorite is most commonly used due to simplicity and safety. Hypochlorous acid $(\mathrm{HOCl})$ dissociates to hypochlorite $\left(\mathrm{OCl}^{-}\right)$with an ionization constant $\left(\mathrm{p} K_{\mathrm{a}}\right)$ of 7.6 at $20^{\circ} \mathrm{C}$. This $\mathrm{pH}$-dependent speciation is critical to disinfection effectiveness because the relative bacterial inactivation efficiency of $\mathrm{HOCl}$ is about 40-80 times that of $\mathrm{OCl}^{-}$(19). Chlorine disinfection has been extensively applied in the harvest and 
postharvest handling of fresh fruits and vegetables for many decades because it is effective, chemically stable, readily available, relatively inexpensive, and easily applied. For example, chlorine has been routinely used for disinfection of vegetables such as lettuce, carrots, and spinach $(12,20,21)$, fruits such as strawberries, apples, cantaloupe, honeydew melons, and tomatoes (22-26), chicken (27), and fish (28). A recent progress in chlorine disinfection is the generation of chlorine water through electrolysis $(29,30)$.

Hydrogen peroxide inactivates or inhibits bacteria directly or indirectly through other cytotoxic oxidizing species such as hydroxyl radicals. Hydrogen peroxide may also be generated in bacteriological media by exposure to light or oxygen, thus becoming an important toxic agent for bacteria (31). The sporicidal activity of hydrogen peroxide coupled with rapid breakdown to water and oxygen makes it a desirable disinfectant for use on some food contact surfaces (32). Hydrogen peroxide has numerous applications in disinfecting vegetables and fruits $(33-35)$ and poultry (36).

However, as ozone, free chlorine, or hydrogen peroxide is brought into contact with the surfaces of food, there is potential for these oxidants to react with the interior body of food, thus reducing the contents of some biologically beneficial nutrients (e.g., antioxidants). It was reported that the mean concentration of reduced glutathione (GSH) significantly decreased when various foods including grapefruit, tomatoes, spinach, carrots, apples, peaches, and sweet potatoes were processed (37). Hydrogen peroxide could break down plant cells isolated from tomato, cucumber, and soybean through oxidation of cell wall polysaccharides (38). When GSH in aqueous solution reacted with hydrogen peroxide, most of the cysteine contained in the GSH was oxidized to the monoxide or dioxide, and some cysteine was even directly oxidized to sulfinic acid (39). Ozone treatment could result in a $40 \%$ reduced emission of volatile esters in postharvest strawberries (13) and a decrease of 16$25 \%$ of ascorbic acid content in potatoes, carrots, and cabbage (40). It is reasonably suspected, therefore, that some biologically important antioxidants (e.g., biothiols) contained in vegetables or fruits may get decomposed upon exposure to disinfectants.

Vegetables contain varied concentrations of important biothiols that serve as strong antioxidants once consumed by humans. Biothiols are a type of mercaptan having a sulfhydryl functional group and are among the most important antioxidants that protect human cells against oxidative damage which leads potentially to cancers, Alzheimer's disease, and other maladies $(41,42)$. These important biothiols include L- $\gamma$-glutamyl-Lcysteinylglycine (reduced glutathione, or GSH), $\gamma$-L-glutamylL-cysteine (GGC), cysteine (CYS), homocysteine (HCYS), captopril (CAP), and $N$-acetyl-L-cysteine (NAC). The chemical structure, molecular formula, molecular weight, and CAS number of these biothiols and GSSG, the primary oxidation product of GSH, are summarized in Table 1. Our recent work has shown, for example, that the biothiol contents ranged from 3 to $349 \mathrm{nmol} / \mathrm{g}$ (wet weight) in a variety of vegetables (43).

The purpose of this study was to examine the impact of ozone (gaseous- and aqueous-phase) and other disinfectants (including free chlorine and hydrogen peroxide) on the bulk concentrations of GSH, GGC, CYS, HCYS, CAP, and NAC in a suite of vegetables consumed daily. The level of GSSG was also examined prior to and after disinfection as an indicator of oxidative stress in terms of the ratio of GSH to GSSG. Spinach, green bean, asparagus, cucumber, and red pepper were selected for this study because they have relatively high levels of biothiols as determined in our previous work (43).

\section{MATERIALS AND METHODS}

Reagents and Chemicals. HPLC grade acetonitrile, acetic acid, and $o$-phosphoric acid and certified ACS grade boric acid, hydrochloric acid, sodium hydroxide, sodium phosphate $(99.9 \%)$, sodium phosphate monobasic (99.5\%), and hydrogen peroxide (ca. $30 \mathrm{wt} \%$ ) were purchased from Fisher Scientific (Fairlawn, NJ). GSH, GGC, NAC, CAP, CYS, HCYS, GSSG, NPM, 1-serine, trizma hydrochloride, diethylenetriaminepentaacetic acid (DETAPAC), potassium indigo trisulfonate, potassium permanganate $(99.3 \%)$, and sodium hypochlorite (>4 wt \%) were purchased from either Sigma (St. Louis, MO) or Aldrich (Milwaukee, WI). Sodium oxalate was obtained from Acros Organics (Fairlawn, NJ) as a primary standard to titrate the concentration of potassium permanganate. Milli-Q (MQ) water with a resistivity $>18.2 \mathrm{M} \cdot \mathrm{cm}$ was produced by a Simplicity 185 water purification system (Millipore Co., Bedford, MA) to prepare HPLC mobile phases and biothiol standard solutions.

Vegetables. A suite of vegetables including spinach (Spinacia oleracea), green bean (Phaseolus vulgaris), green asparagus (Asparagus officinalis), cucumber (Cucumis sativus), and red bell pepper (Capsicum аппиит) were obtained from a local grocery store in Rolla, MO. All of the study vegetables from this supplier were simply rinsed three times with tap water for cleaning purposes, and none were treated by any disinfectant. In our reaction systems, these vegetables were treated whole and then cut up into about $0.5 \mathrm{~g}$ pieces for biothiol analysis.

Reaction Systems. Batch reactions were conducted for free chlorine and hydrogen peroxide in a large glass jar reactor containing $10 \mathrm{~L}$ of oxidant solution as a reaction reservoir. The oxidant concentration was maintained approximately constant (i.e., $515-485 \mathrm{mg} / \mathrm{L}$ free chlorine, $5.10-4.90 \% \mathrm{H}_{2} \mathrm{O}_{2}$ ) throughout the course of reaction. Vegetables were soaked in the oxidant solution with a porous ceramic plate (nonreactive toward the oxidants) sitting on the top to maintain submersion of the vegetables. The working solutions of free chlorine and hydrogen peroxide were prepared by diluting the purchased sodium hypochlorite ( $>4 \mathrm{wt} \%$ ) and hydrogen peroxide (ca. $30 \mathrm{wt} \%$ ) solutions with distilled water to reach concentrations of $500 \pm 15 \mathrm{mg} / \mathrm{L}$ and $5.0 \pm 0.10 \%$ (by weight), respectively, with the $\mathrm{pH}$ of both solutions adjusted to 7.6.

Semibatch reactions were conducted for aqueous-phase ozone, whose setup is illustrated in Figure 1A. An ozone gas stream was produced from compressed pure oxygen by a GLS-1 ozone generator (PCIWEDECO Environmental Technologies, West Caldwell, NJ). The ozone stream was bubbled through a stone diffuser into a glass bottle containing $4 \mathrm{~L}$ of buffered MQ water $(5 \mathrm{mM}$ sodium phosphate, adjusted to $\mathrm{pH}$ 7.6). The dissolved ozone solution then circulated into the $10 \mathrm{~L}$ reactor through an overflow outlet on one side of the glass bottle. A pump was utilized to continuously circulate the working solution between the $4 \mathrm{~L}$ bottle and the $10 \mathrm{~L}$ reactor. The system was allowed to equilibrate and stabilize for $20 \mathrm{~min}$ to reach a steady-state concentration of dissolved ozone before the vegetables were placed into the reactor.

Continuous reactions were carried out for gaseous-phase ozone, whose setup is illustrated in Figure 1B. A small ozone generator (AquaZone $50 \mathrm{mg} / \mathrm{h}$, Red Sea Fish Pharm Ltd., Houston, TX) was used to generate a low-concentration ozone gas stream (i.e., $40 \mathrm{ppm}$ ) from compressed air. The flow rate of the compressed air was maintained at 5.0 SLPM (standard liters per minute) with a mass flow controller (2900 Series, Tylan General, Inc., Austin, TX). The ozone gas stream then passed through a humidifier containing about $50 \mathrm{~mL}$ of MQ water to get saturated with water. A saturated humidity not only minimizes the gas-stripping loss of water originally contained in the vegetables, but also enhances the efficiency of bacterial inactivation. It was reported that the inactivation rates of Bacillus spores by gaseous-phase ozone increased with increasing exposure humidity (44). The vegetables were hung in a $5 \mathrm{~L}$ glass reactor with Teflon lines (nonreactive with ozone) to ensure sufficient contact of the vegetable surface with ozone gas.

Common oxidant dosages and contact times were employed in this work. Specifically, the dosages of free chlorine, hydrogen peroxide and aqueous-phase ozone were $500 \pm 15 \mathrm{mg} / \mathrm{L}, 5.0 \pm 0.10 \%$ (by weight), and $8.0 \pm 2.0 \mathrm{mg} / \mathrm{L}$, respectively, with a contact time of 30 min at $\mathrm{pH} 7.6$ for each disinfectant. The working solution was gently mixed with a magnetic stir plate to eliminate an oxidant concentration 
Table 1. Physicochemical Properties of the Study Biothiols and Oxidized Glutathione (GSSG)

\begin{tabular}{|c|c|c|c|}
\hline Code & Biothiol & Structure & $\mathrm{MF} / \mathrm{MW} / \mathrm{CAS} \#$ \\
\hline GSH & $\begin{array}{l}\text { L- } \gamma \text {-glutamyl-L- } \\
\text { cysteinly glycine, } \\
\text { or reduced } \\
\text { glutathione }\end{array}$ & 0 & $\begin{array}{c}\mathrm{C}_{10} \mathrm{H}_{17} \mathrm{~N}_{3} \mathrm{O}_{6} \mathrm{~S} \\
307.32 \\
70-18-8\end{array}$ \\
\hline NAC & N-acetyl-L-cysteine & NHAC & $\begin{array}{c}\mathrm{C}_{5} \mathrm{H}_{9} \mathrm{NO}_{3} \mathrm{~S} \\
163.19 \\
616-91-1\end{array}$ \\
\hline CAP & captopril & $\mathrm{Me}$ & $\begin{array}{l}\mathrm{C}_{9} \mathrm{H}_{15} \mathrm{NO}_{3} \mathrm{~S} \\
217.28 \\
62571-86-2\end{array}$ \\
\hline CYS & cysteine & $\mathrm{NH}_{2}$ & $\begin{array}{c}\mathrm{C}_{3} \mathrm{H}_{7} \mathrm{NO}_{2} \mathrm{~S} \\
121.15 \\
52-90-4\end{array}$ \\
\hline HCYS & homocysteine & $\mathrm{NH}_{2}$ & $\begin{array}{c}\mathrm{C}_{4} \mathrm{H}_{9} \mathrm{NO}_{2} \mathrm{~S} \\
135.18 \\
454-29-5\end{array}$ \\
\hline GGC & $\begin{array}{c}\gamma \text {-L-Glutamyl-L- } \\
\text { cysteine }\end{array}$ & $\mathrm{O}_{2} \mathrm{H} \quad 0$ & $\begin{array}{c}\mathrm{C}_{8} \mathrm{H}_{14} \mathrm{~N}_{2} \mathrm{O}_{5} \mathrm{~S} \\
250.27 \\
686-58-8\end{array}$ \\
\hline GSSG & $\begin{array}{c}\text { glutathione disulfide, } \\
\text { or oxidized } \\
\text { glutathione }\end{array}$ & & $\begin{array}{c}\mathrm{C}_{20} \mathrm{H}_{32} \mathrm{~N}_{6} \mathrm{O}_{12} \mathrm{~S}_{2} \\
612.63 \\
27025-41-8\end{array}$ \\
\hline
\end{tabular}

gradient toward the vegetable surface. For gaseous-phase ozone, a concentration of $40 \mathrm{ppm}$ and a contact time of $1 \mathrm{~h}$ were utilized. Chemical analysis confirmed that the oxidant concentration remained nearly constant throughout the course of reaction.

Oxidant Analysis. The total chlorine concentration was determined using Hach DPD Method 8167 with a DR/2010 portable spectrophotometer (Hach Co., Loveland, CO) after appropriate dilution. The hydrogen peroxide concentration was titrated with potassium permanganate, whose concentration was first standardized by a primary standard, sodium oxalate. The aqueous ozone concentration was measured by an indigo colorimetric method (45) with a Cary 50 Conc spectrophotometer (Varian Australia Pty Ltd., Australia). The small ozone generator was standardized by a modified indigo colorimetric method which is suitable for determination of the ozone concentration in the gas phase by utilizing a humidifier. Specifically, $200 \mathrm{~mL}$ of an indigo solution $(0.12 \mathrm{mM})$ was added to the humidifier. An ozone gas stream was allowed to pass through the humidifier for $2 \mathrm{~min}$, where ozone reacted rapidly with the indigo solution. The molar absorptivity of indigo decreased by $20000 \mathrm{M}^{-1} \cdot \mathrm{cm}^{-1}$ at $600 \mathrm{~nm}$ with respect to each mole of ozone consumed (45). The gaseous ozone concentration was then determined on the basis of the decrease of the indigo absorbance.

HPLC System. A Finnigan high-performance liquid chromatography (HPLC) system (Thermo Electron Co., San Jose, CA), which consisted of a vacuum membrane degasser, an injection valve with a $5 \mu \mathrm{L}$ injection filling loop, two gradient pumps, an autosampler, and a fluorescence detector, was used to determine the concentrations of biothiols and GSSG. The fluorescence detector was operated at an 

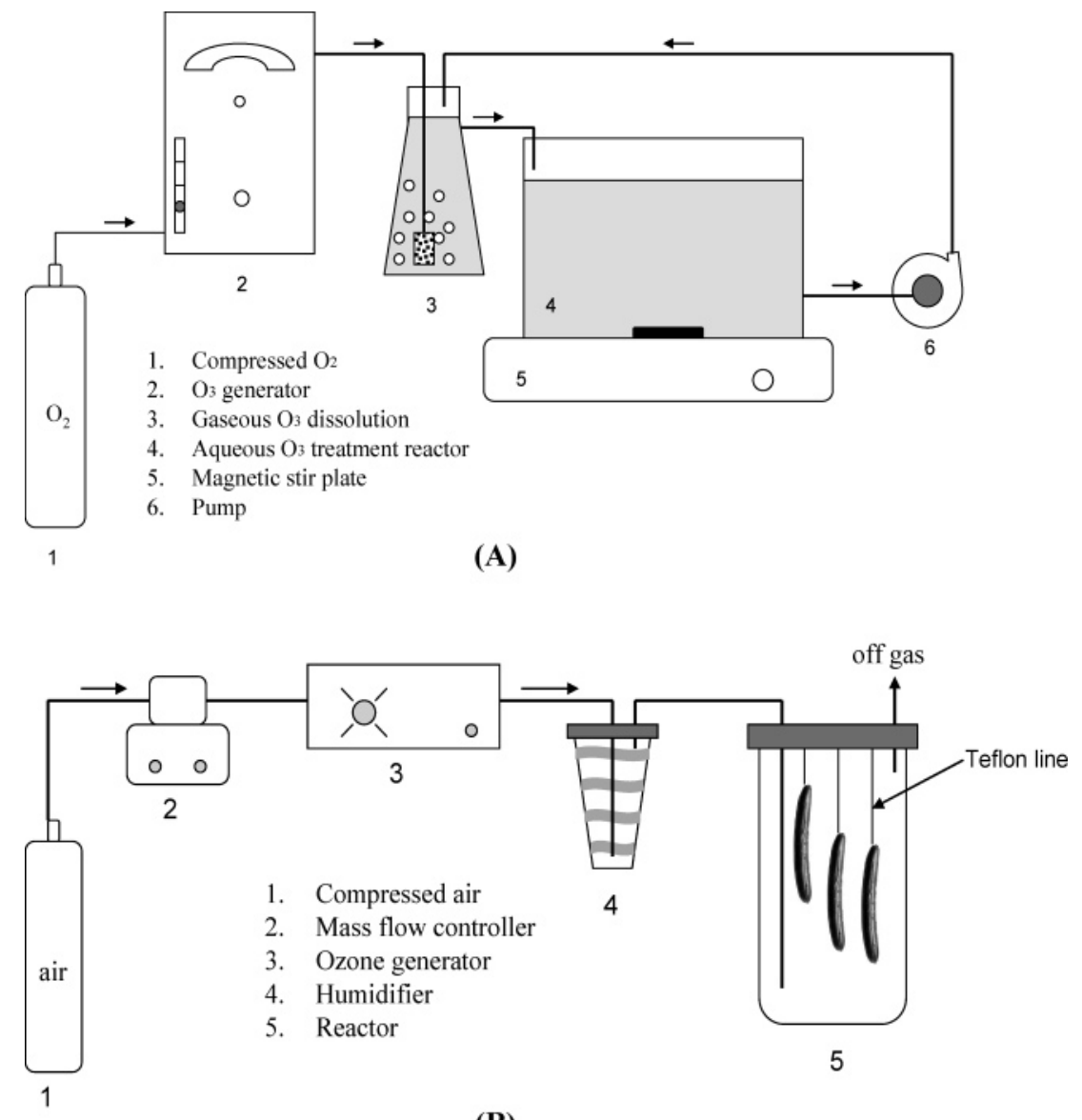

(B)

Figure 1. Schematic diagram of ozone treatment systems: (A) aqueous-phase ozone and (B) gaseous-phase ozone.

excitation wavelength of $330 \mathrm{~nm}$ and an emission wavelength of 376 nm. A reversed-phase Reliasil ODS-1 $\mathrm{C}_{18}$ column $(5 \mu \mathrm{m}, 250 \times 4.6$ $\mathrm{mm}$ ) (Column Engineering, Ontario, CA) was utilized for biothiol separation. The mobile phase consisted of $70 \%$ acetonitrile and $30 \%$ MQ water, and was adjusted to approximately $\mathrm{pH} 2.5$ by addition of 1 $\mathrm{mL}$ of acetic acid and $1 \mathrm{~mL}$ of $o$-phosphoric acid per liter of mobile phase. Prior to use, the mobile phase was vacuumed under sonication for $30 \mathrm{~min}$ to drive out dissolved gas bubbles.

Biothiol Analysis. Because our preliminary work showed that the biothiol contents for a batch of a vegetable may vary significantly from one sample to another, 15 vegetables were analyzed in replicates for both control (untreated) and disinfectant-treated samples. Specifically, samples were prepared in five replicates, with each replicate containing a mix of three cutlets (about $0.5 \mathrm{~g}$ per piece) cut from individual wholetreated vegetables. A cutlet represented a piece of vegetable cut from the central part of a vegetable body. For cucumber, a cutlet was cut about $1 \mathrm{~cm}$ deep from the central skin into the flesh. For other study vegetables, a cutlet was cut across the whole central body. As a result, the analyzed biothiol level represented the level over the whole body of spinach, green bean, asparagus, and red pepper, but only represented the level in the outer $1 \mathrm{~cm}$ rim of the cucumber. Compared to other study vegetables, cucumber has a much thicker body. It was reasonably presumed that the oxidant penetration beyond the $1 \mathrm{~cm}$ cucumber flesh was insignificant. The three-cutlet mix was placed in a serine borate buffer (SBB) to prevent potential oxidation of biothiols by atmospheric oxygen. The SSB buffer comprised $100 \mathrm{mM}$ Tris- $\mathrm{HCl}, 10 \mathrm{mM}$ borate, $5 \mathrm{mM}$ serine, and $1 \mathrm{mM}$ DETAPAC with the final $\mathrm{pH}$ adjusted to 7.0 by concentrated $\mathrm{NaOH}$ solution. The samples were homogenized in the SBB buffer with a Tissue-Tearor (Biospec Products, Inc., Bartlesville, $\mathrm{OK}$ ) on ice for $2 \mathrm{~min}$ and centrifuged at $10000 \mathrm{~g}$ for $15 \mathrm{~min}$ at a controlled temperature of $4{ }^{\circ} \mathrm{C}$ to extract biothiols out of the vegetables. Thereafter, $40 \mu \mathrm{L}$ of supernatant was withdrawn and derivatized with $N$-(1-pyrenylmaleimide) (NPM), which reacts with free sulfhydryl groups of the biothiols to form fluorescent derivatives. Each sample was diluted with $210 \mu \mathrm{L}$ of MQ water and derivatized with $750 \mu \mathrm{L}$ of
NPM (1 mM in acetonitrile). The resulting solution was vigorously mixed and allowed to react at ambient temperature for $5 \mathrm{~min}$. $\mathrm{HCl}$ solution $(10 \mu \mathrm{L}, 2 \mathrm{M})$ was then added inside to stop the reaction. After being filtered through a $0.20 \mu \mathrm{m}$ nylon filter (Advantec MFS, Inc., Dublin, CA) using a $3 \mathrm{~mL}$ syringe, the derivatized samples were injected onto the HPLC system.

The biothiol-NPM derivatives were separately eluted from the HPLC column with the mobile phase flowing isocratically at a rate of $1 \mathrm{~mL} / \mathrm{min}$. GSH, GGC, NAC, CAP, CYS, and HCYS could be determined concurrently since all these biothiols form fluorescent derivatives with NPM. The biothiol-NPM peaks were quantified with Thermo LC software (Thermo Electron Co., San Jose, CA). The linearity of standard calibration curves was confirmed over a concentration range of $0-10 \mu \mathrm{M}$ for each biothiol in a mixture. A typical chromatogram of the study biothiols is shown in Figure 2A. The biothiol-NPM derivatives were eluted from the HPLC column in the following sequence: NAC (3.47 min), CAP (3.99 min), GSH (8.24 $\mathrm{min})$, GGC (9.42 $\mathrm{min})$, CYS (10.74 $\mathrm{min})$, and HCYS (12.79 $\mathrm{min})$.

GSSG Analysis. GSSG, the primary oxidation product of GSH, was determined by reacting $84 \mu \mathrm{L}$ of vegetable supernatant with $16 \mu \mathrm{L}$ of 2-vinylpyridine (6.25\% in ethanol) for $1 \mathrm{~h}$ to block any preexisting GSH. After the reaction, $95 \mu \mathrm{L}$ of an NADPH solution $(2 \mathrm{mg} / \mathrm{mL})$ and $5 \mu \mathrm{L}$ of a glutathione reductase solution ( 2 units $/ \mathrm{mL}$ ) were added sequentially. An aliquot of $100 \mu \mathrm{L}$ of the resulting solution was quickly withdrawn and mixed with $150 \mu \mathrm{L}$ of MQ water and $750 \mu \mathrm{L}$ of NPM ( $1 \mathrm{mM}$ in acetonitrile) for derivatization. After $5 \mathrm{~min}$, the reaction was stopped by adding $5 \mu \mathrm{L}$ of $\mathrm{HCl}$ solution $(2 \mathrm{M})$. The samples were then filtered through a $0.20 \mu \mathrm{m}$ nylon filter and injected onto the HPLC system. A typical GSSG chromatogram is shown in Figure 2B, where the GSSG-NPM derivative was eluted from the HPLC column at 8.63 $\min$.

Bacteria Enumeration. To enumerate bacteria, both control (untreated) and disinfectant-treated vegetable samples were washed with a phosphate buffer in sterilized glass beakers of suitable sizes. The washing process consisted of 10 min of soaking and 5 min of gentle 


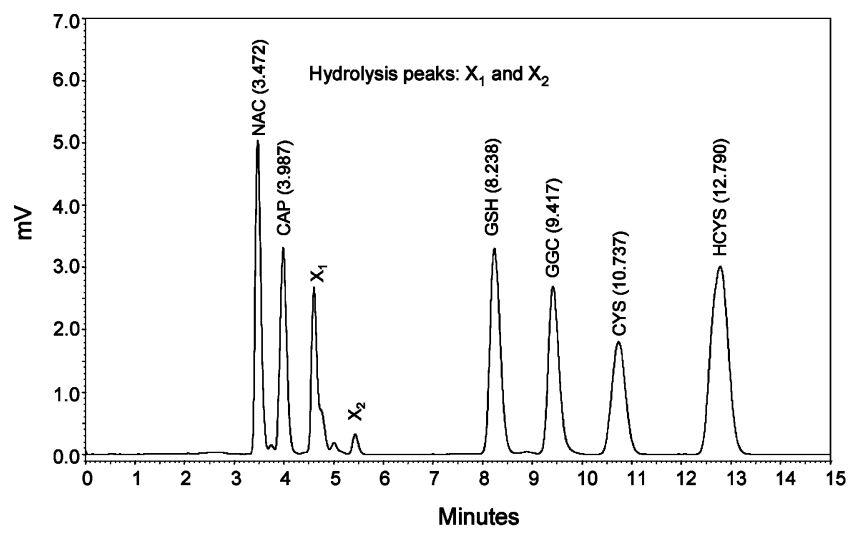

(A)

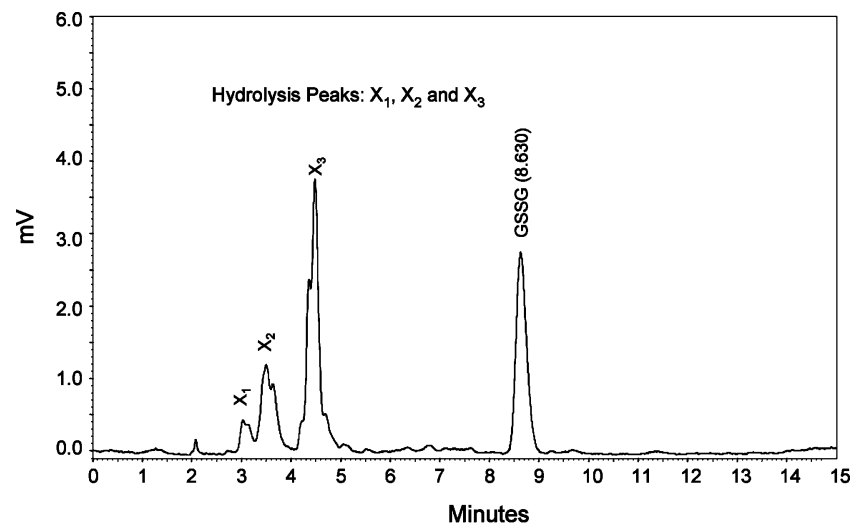

(B)

Figure 2. HPLC chromatograms: (A) NAC, CAP, GSH, GGC, CYS, and HCYS and (B) GSSG. Retention times are given in minutes in parentheses.

shaking. Each liter of the phosphate buffer consisted of $140 \mathrm{~mL}$ of 0.2 $\mathrm{M} \mathrm{NaH}{ }_{2} \mathrm{PO}_{4}, 360 \mathrm{~mL}$ of $\mathrm{Na}_{2} \mathrm{HPO}_{4}$, and $500 \mathrm{~mL}$ of MQ water with a final $\mathrm{pH}$ value of $7.2 \pm 0.1$ (46). The volumes of the phosphate buffer used for vegetable washing were $200,40,40,500$, and $500 \mathrm{~mL}$ for spinach, green bean, asparagus, cucumber, and red pepper, respectively. The standard most probable number (MPN) analysis was performed with brain heart infusion medium (37 g/L, Beckton-Dickinson). The medium tubes, glass beakers, buffer solutions, pipet tips, and volumetric cylinders used for the MPN analysis were all autoclaved at $2 \mathrm{~atm}$ (absolute) and $121{ }^{\circ} \mathrm{C}$ for $30 \mathrm{~min}$ prior to use. Sample serial dilution was carried out aseptically in a laminar flow biological safety hood (Plymouth, MN). The MPN analysis for each vegetable was performed with duplicate samples, and each sample was analyzed in triplicate as 10 -fold serial dilutions down to $10^{-10}$. The serially diluted medium tubes were then incubated in a GCA/Precision Scientific Thelco oven (model 6, Chicago, IL) at $37{ }^{\circ} \mathrm{C}$ for 3 days. Tubes exhibiting visual growth after this incubation period were considered as positive. Final enumeration of bacteria was completed by comparing the distribution pattern of the positive tubes with a standard statistical MPN table (47).

\section{RESULTS}

Oxidation of Biothiols. Because a majority of the biothiols exist in the interior body of the vegetables, a possible hypothesis is that all of the oxidants should be consumed near the vegetable surface, thereby protecting most of the biothiols against oxidation. Our results have shown, however, that under typical contacting conditions the disinfectants can significantly reduce the concentrations of these nutritionally important biothiols in vegetables. The extent of biothiol decrease depends on the type of disinfectant, the vegetable, and the biothiol.

Spinach. The impact of disinfectants on the concentrations of biothiols and GSSG for spinach is shown in Figure 3. Three

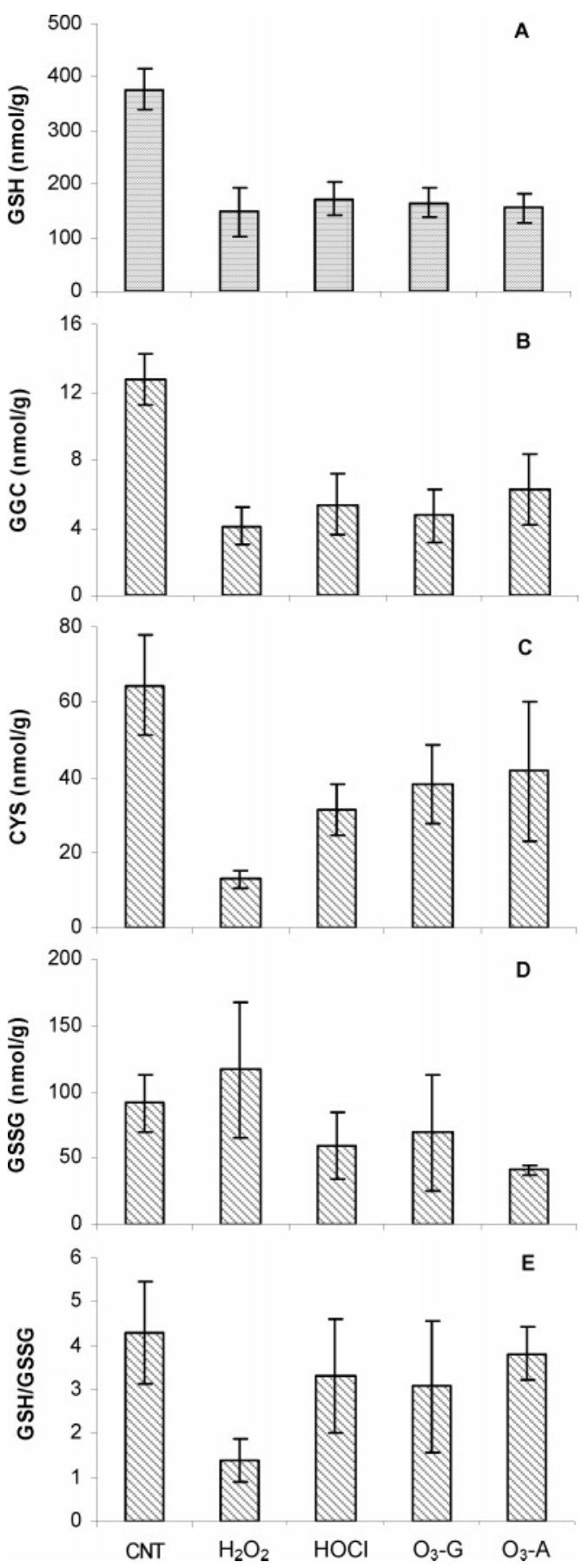

Figure 3. Impact of disinfectants on the concentrations of biothiols and GSSG for spinach: (A) GSH, (B) GGC, (C) CYS, (D) GSSG, and (E) GSH/GSSG ratio. NAC, HCYS, and CAP were not detected in spinach. Experimental conditions: for aqueous reactions, $\left[\mathrm{H}_{2} \mathrm{O}_{2}\right]=5.0 \pm 0.10 \%$, $[\mathrm{HOCl}]=500 \pm 15 \mathrm{mg} / \mathrm{L},\left[\mathrm{O}_{3}\right]_{\mathrm{A}}=8.0 \pm 2.0 \mathrm{mg} / \mathrm{L}$, contact time $30 \mathrm{~min}$, $\mathrm{pH} 7.6$; for gaseous reactions, $\left[\mathrm{O}_{3}\right]_{\mathrm{G}}=40 \mathrm{ppm}$, contact time $60 \mathrm{~min}$. Error bars represent the standard deviation of five replicates, with each replicate containing a mix of three cutlets from individual vegetables.

biothiols were detected in spinach including GSH, GGC, and CYS with concentrations in the control samples of $377.2 \pm 37.7$, $12.8 \pm 1.5$, and $64.6 \pm 13.2 \mathrm{nmol} / \mathrm{g}$ (wet weight), respectively. A significant decrease in these biothiol levels was observed for all disinfectants investigated (except for CYS with aqueousphase ozone) (Figure 3A-C). Results indicate that the mean decrease percentages of GSH, GGC, and CYS are $61 \%, 68 \%$, and $80 \%$ by hydrogen peroxide, $54 \%, 58 \%$, and $51 \%$ by free chlorine, $56 \%, 63 \%$, and $41 \%$ by gaseous-phase ozone, and 
$59 \%, 51 \%$, and $35 \%$ by aqueous-phase ozone, respectively. On average, hydrogen peroxide decreases the mean level of all three biothiols by approximately $70 \%$, and the other disinfectants (free chlorine, gaseous-phase ozone, and aqueous-phase ozone) decrease the mean level of the three biothiols by $48-54 \%$.

Results also show that the mean level of GSSG may either increase or decrease after disinfection (Figure 3D). The level of GSSG in the control samples was measured to be $91.8 \pm$ $21.5 \mathrm{nmol} / \mathrm{g}$. This control value changed to $116.4 \pm 51.4,59.3$ $\pm 24.6,69.0 \pm 43.0$, and $40.8 \pm 4.2 \mathrm{nmol} / \mathrm{g}$ after treatment with hydrogen peroxide, free chlorine, and gaseous- and aqueous-phase ozone, respectively. A portion of GSH can be transformed to GSSG after reacting with the oxidants. However, GSSG still contains reducing functional moieties such as amine and sulfur groups which may get further decomposed by the oxidants. Indeed, it was reported that the disulfide group $(-\mathrm{SS}-)$ contained in GSSG can be oxidized by hydrogen peroxide to various monoxide and dioxide products (i.e., $-\mathrm{SS}$ $(=\mathrm{O})-$ and $\left.-\mathrm{SS}(=\mathrm{O})_{2}-\right)$ or directly to sulfinic acid $\left(-\mathrm{SO}_{2} \mathrm{H}\right)$ (39). The fraction of the monoxide and dioxide products was found to be as high as $45 \%$ at $\mathrm{pH} 7.6$ (39). This indicates that the disulfide group of GSSG can be further oxidized by disinfectants. Therefore, it is hypothesized that the GSSG level reflects an overall result of GSH transformation and potential GSSG decomposition after disinfection. The ratio of GSH to GSSG (reduced glutathione to oxidized glutathione) is a parameter indicating how significant an oxidative stress is. Results further show that the mean GSH/GSSG ratio decreases significantly from $4.3 \pm 1.2$ for the control to $1.4 \pm 0.5$ for hydrogen peroxide and less so for other oxidants (i.e., $3.3 \pm$ 1.3 for free chlorine, $3.1 \pm 1.5$ for gaseous-phase ozone, and $3.8 \pm 0.6$ for aqueous-phase ozone) (Figure 3E). This demonstrates that oxidative stress can be developed in spinach by disinfection with $\mathrm{H}_{2} \mathrm{O}_{2}$.

Green Bean. Similar to spinach, three biothiols including GSH, GGC, and CYS were detected in green bean with baseline concentrations of $309.7 \pm 10.1,15.0 \pm 1.7$, and $6.5 \pm 0.4$ $\mathrm{nmol} / \mathrm{g}$ (wet weight), respectively. The impact of disinfectants on the biothiol concentrations appeared minimal (Figure 4). The mean GSH concentration was decreased by $11 \%$ with hydrogen peroxide and $6 \%$ with free chlorine, while neither gaseous-phase nor aqueous-phase ozone decreased GSH. The mean GGC concentration was reduced by $20 \%$ with free chlorine and $26 \%$ by aqueous-phase ozone, while neither hydrogen peroxide nor gaseous-phase ozone decreased GGC. CYS was the least removed biothiol. Less decrease in biothiol levels was observed in green bean than in spinach because green bean has a relatively thick pod which protects interior biothiols against oxidative damage.

The level of GSSG in the control samples was determined to be $9.7 \pm 2.3 \mathrm{nmol} / \mathrm{g}$, and it increased to $17.6 \pm 2.0,12.7 \pm$ $2.7,10.2 \pm 1.0$, and $10.2 \pm 0.7 \mathrm{nmol} / \mathrm{g}$ after treatment with hydrogen peroxide, free chlorine, and gaseous- and aqueousphase ozone, respectively (Figure 4D). The $\mathrm{H}_{2} \mathrm{O}_{2}$-treated sample showed a statistically significant difference in the mean GSSG level compared with the control sample. Correspondingly, the mean GSH/GSSG ratio significantly decreased from $33.7 \pm 9.6$ for the control to $15.9 \pm 3.8$ for hydrogen peroxide and less so for other oxidants (i.e., $23.4 \pm 5.9$ for free chlorine, $31.0 \pm 2.4$ for gaseous-phase ozone, and $30.4 \pm 2.9$ for aqueous-phase ozone) (Figure 4E). The most notable oxidative stress was developed after green bean was treated with hydrogen peroxide in terms of the GSH/GSSG ratio.
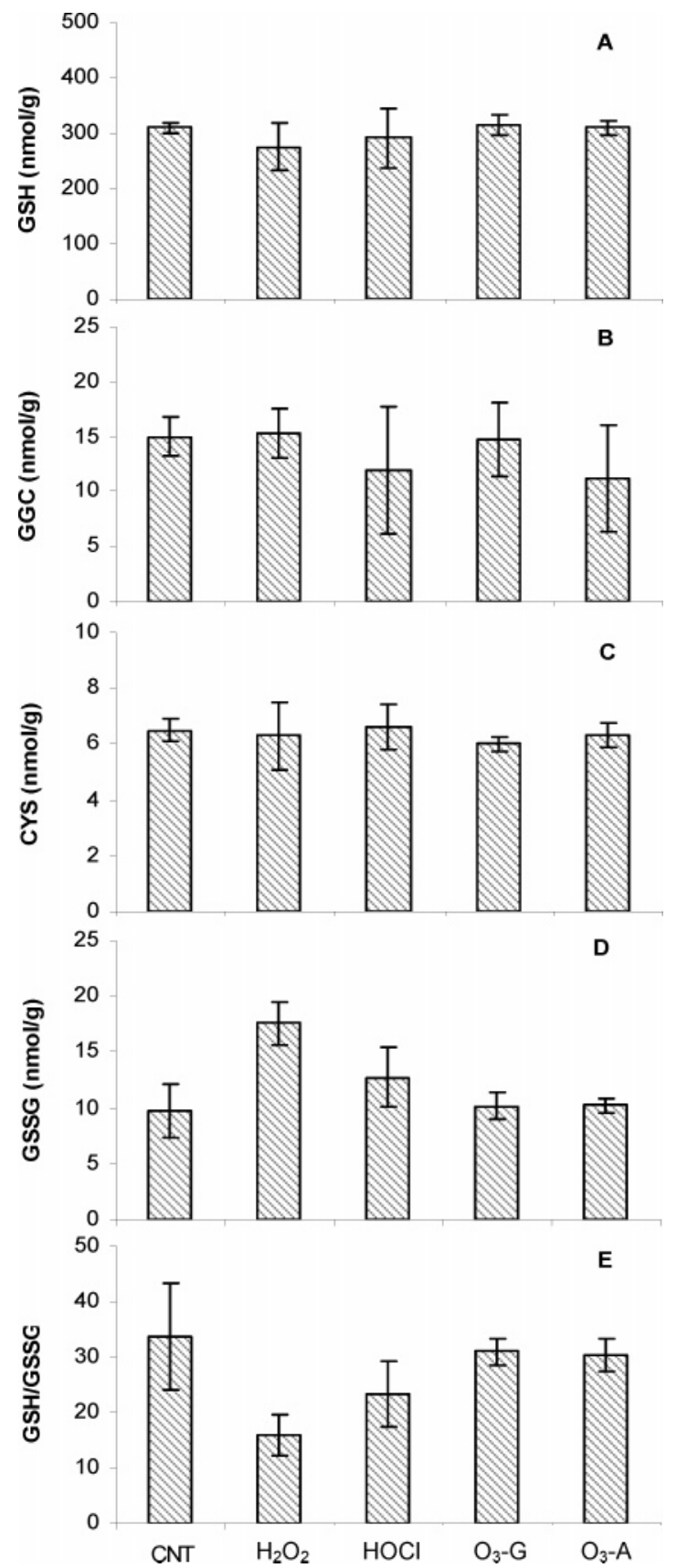

Figure 4. Impact of disinfectants on the concentrations of biothiols and GSSG for green bean: (A) GSH, (B) GGC, (C) CYS, (D) GSSG, and (E) GSH/GSSG ratio. NAC, HCYS, and CAP were not detected in green bean. Experimental conditions and error bars are the same as those for Figure 3.

Asparagus. Five biothiols were detected in asparagus including GSH, CYS, HCYS, CAP, and NAC with baseline concentrations of $627.0 \pm 52.0,39.9 \pm 12.9,4.0 \pm 1.1,68.4 \pm 10.1$, and $106.4 \pm 12.9 \mathrm{nmol} / \mathrm{g}$ (wet weight), respectively. Only GGC was not found in asparagus. Figure 5 shows the impact of disinfectants on the concentrations of biothiols and GSSG for asparagus. Results indicate that disinfection exerts minimal effect on biothiol concentrations (Figure 5). If averaged over four disinfection technologies, the largest decrease in mean biothiol concentration occurred for HCYS (15\%), while relatively small decreases occurred for GSH (10\%), CYS (7\%), CAP $(5 \%)$, and NAC (3\%). In particular, a notable decrease in mean biothiol concentration ( $>10 \%$ ) was observed for GSH (15\% with hydrogen peroxide and $14 \%$ with gaseous-phase ozone), CYS 

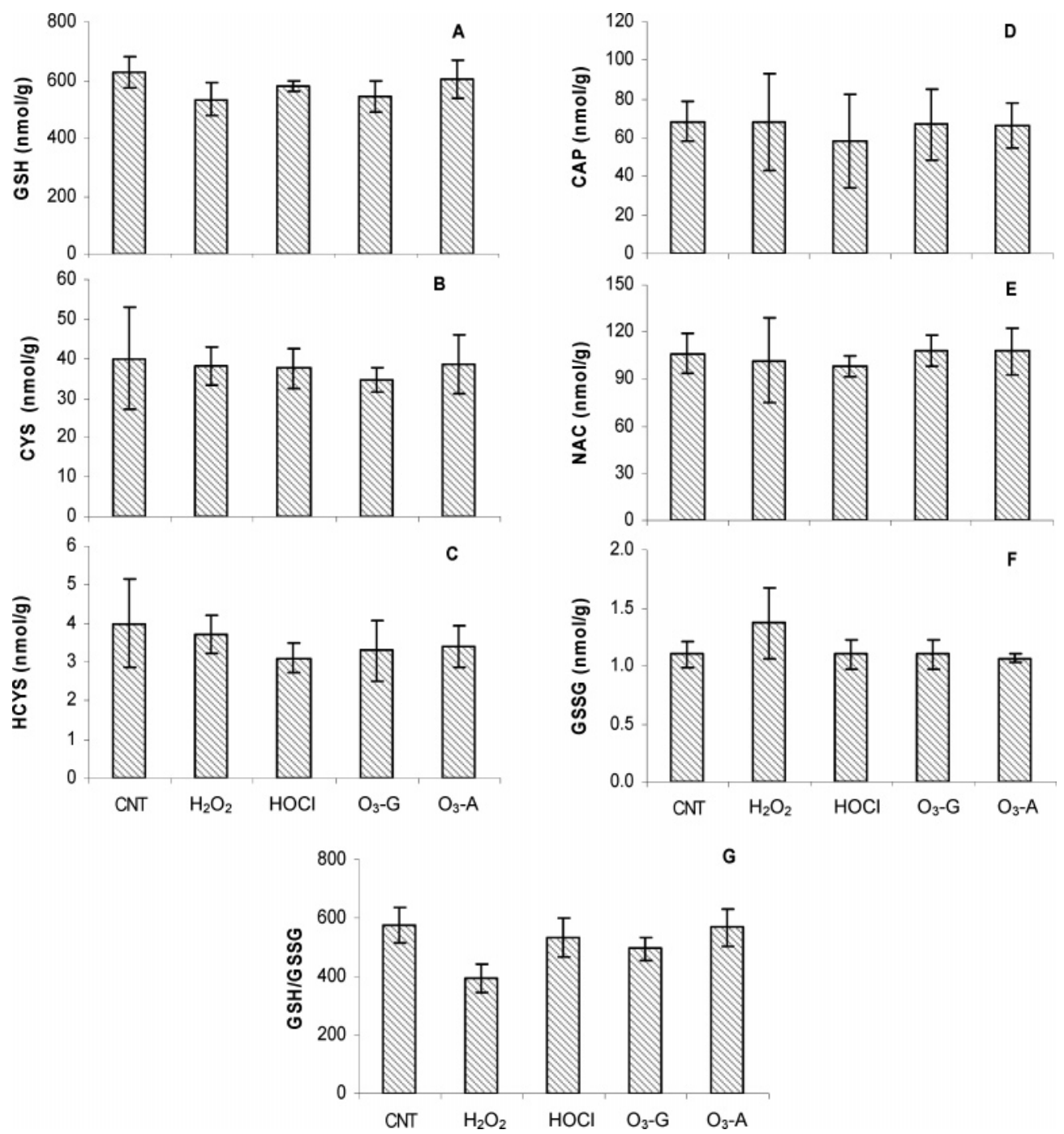

Figure 5. Impact of disinfectants on the concentrations of biothiols and GSSG for asparagus: (A) GSH, (B) CYS, (C) HCYS, (D) CAP, (E) NAC, (F) GSSG, and (G) GSH/GSSG ratio. GGC was not detected in asparagus. Experimental conditions and error bars are the same as those for Figure 3 .

(13\% with gaseous-phase ozone), HCYS (21\% with free chlorine, $17 \%$ with gaseous-phase ozone, and $15 \%$ with aqueous-phase ozone), and CAP (15\% with free chlorine) (Figure 5A-E). NAC was the least removed biothiol.

Relatively small levels of GSSG (ca. $1.0 \mathrm{nmol} / \mathrm{g}$ ) were detected in asparagus for both control and treated samples (Figure 5F). The apparent increase in mean GSSG level was only observed after hydrogen peroxide treatment, increasing from $1.1 \pm 0.1$ to $1.4 \pm 0.3 \mathrm{nmol} / \mathrm{g}$. The other three disinfectants had no effect on GSSG. The most significant change of the GSH/GSSG ratio was observed for hydrogen peroxide, decreasing from $574.6 \pm 61.0$ for the control to $396.9 \pm 48.5$ (Figure 5G). The GSH/GSSG ratios for free chlorine and gaseous- and aqueous-phase ozone were determined to be $531.1 \pm 66.4,494.3$ \pm 36.8 , and $566.8 \pm 64.2$, respectively. The decrease of the GSH/GSSG ratio in asparagus is primarily caused by the decrease of GSH levels.

Cucumber. Three biothiols including GSH, NAC, and CYS were detected in cucumber with baseline concentrations of 68.8 $\pm 0.8,8.2 \pm 3.3$, and $11.5 \pm 2.2 \mathrm{nmol} / \mathrm{g}$ (wet weight), respectively. Cucumber contains much lower biothiol concentrations per unit weight than spinach, green bean, and asparagus. Figure 6 shows the impact of disinfectants on the concentrations of biothiols and GSSG for cucumber. Results indicate that the mean concentrations of GSH and NAC are decreased by $4 \%$ and $37 \%$, respectively, if averaged over four disinfection technologies (Figure 6A,B). The mean concentration of CYS is not changed statistically (Figure 6C).

Results also indicate that the level of GSSG is minimal in cucumber, exhibiting a baseline concentration as low as 0.30 $\pm 0.16 \mathrm{nmol} / \mathrm{g}$. After treatment, the mean concentration of GSSG increased a little to $0.42 \pm 0.10,0.47 \pm 0.17,0.41 \pm$ 0.12 , and $0.39 \pm 0.11 \mathrm{nmol} / \mathrm{g}$ for hydrogen peroxide, free chlorine, and gaseous- and aqueous-phase ozone, respectively (Figure 6D). In correspondence, the GSH/GSSG ratio decreased from $274.1 \pm 37.7$ for the control to $154.6 \pm 24.3$ for hydrogen peroxide, $146.7 \pm 57.1$ for free chlorine, $182.0 \pm 48.6$ for gaseous-phase ozone, and $189.7 \pm 49.3$ for aqueous-phase ozone (Figure 6E). The apparent decrease in the GSH/GSSG ratio is mainly caused by the increase of GSSG levels after disinfection.

Red Pepper. The impact of disinfectants on the concentrations of biothiols and GSSG is shown in Figure 7 for red pepper. Two biothiols were detected in red pepper including GSH and CYS with baseline concentrations of $72.8 \pm 3.6$ and $320.0 \pm$ 43.6, respectively. Red pepper contains much more CYS than any other vegetable investigated. Results indicate that the mean level of GSH is significantly decreased by the disinfectants (i.e., $71 \%$ with hydrogen peroxide, $60 \%$ with free chlorine, $67 \%$ with gaseous-phase ozone, and $65 \%$ with aqueous-phase ozone), as shown in Figure 7A. The decrease of the mean CYS level is 

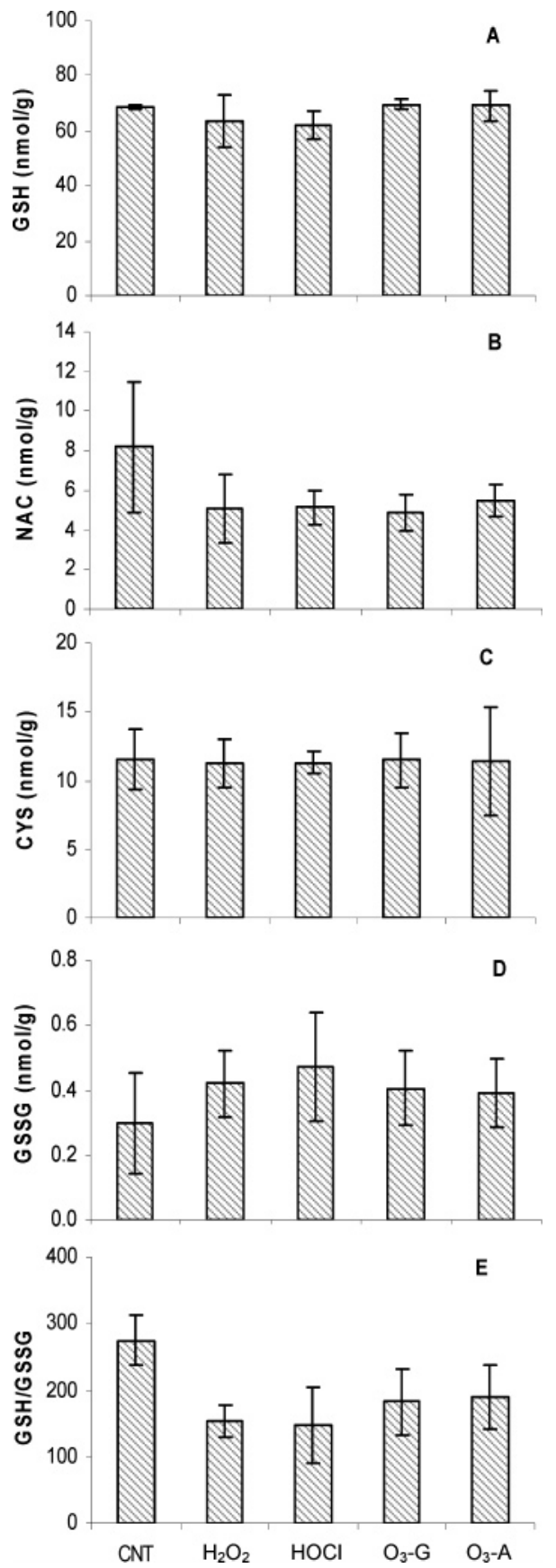

Figure 6. Impact of disinfectants on the concentrations of biothiols and GSSG for cucumber: (A) GSH, (B) NAC, (C) CYS, (D) GSSG, and (E) GSH/GSSG ratio. GGC, HCYS, and CAP were not detected in cucumber. Experimental conditions and error bars are the same as those for Figure 3.

$23 \%$ for aqueous-phase ozone, and ranges from $12 \%$ to $14 \%$ for the other three disinfectants (Figure 7B). If averaged over four disinfection technologies, the mean GSH level is significantly decreased by $66 \%$ and the mean CYS level is decreased by $15 \%$.

A small level of GSSG was detected in red pepper with a concentration of $1.33 \pm 0.14 \mathrm{nmol} / \mathrm{g}$ in control samples. The mean concentration of GSSG slightly decreased to $1.11 \pm 0.22$, $1.05 \pm 0.15,0.91 \pm 0.08$, and $1.10 \pm 0.27 \mathrm{nmol} / \mathrm{g}$ after treatment with hydrogen peroxide, free chlorine, and gaseousand aqueous-phase ozone, respectively (Figure 7C). The GSH/ GSSG ratio significantly decreased from $52.7 \pm 13.9$ for the control to $20.6 \pm 8.5$ for hydrogen peroxide, $26.8 \pm 4.1$ for

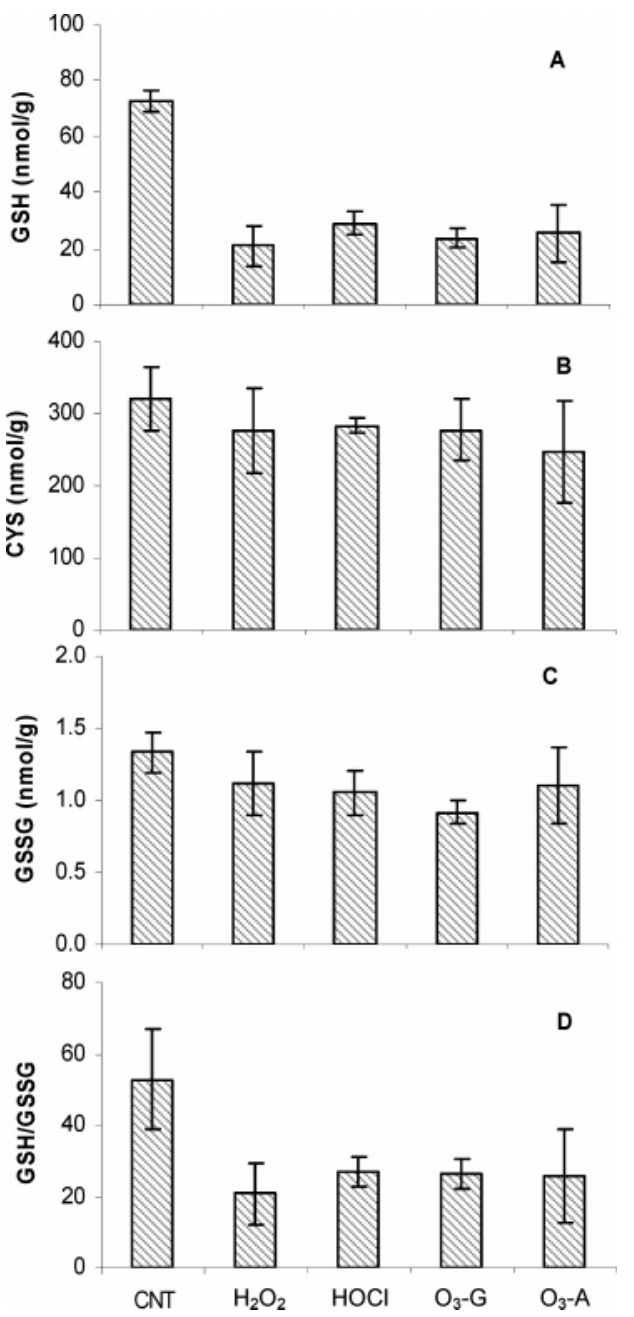

Figure 7. Impact of disinfectants on the concentrations of biothiols and GSSG for red pepper: (A) GSH, (B) CYS, (C) GSSG, and (D) GSH/ GSSG ratio. GGC, NAC, HCYS, and CAP were not detected in red pepper. Experimental conditions and error bars are the same as those for Figure 3.

free chlorine, $26.2 \pm 4.3$ for gaseous-phase ozone, and $25.6 \pm$ 13.2 for aqueous-phase ozone. The apparent decrease of the GSH/GSSG ratio is primarily caused by the decrease of GSH levels after disinfection.

Disinfection of Bacteria. The impact of disinfectants on bacterial inactivation was concurrently investigated, as shown in Figure 8. The number of total bacteria was counted by the MPN method to illustrate an overall effectiveness of the disinfection technologies. Results indicate that the efficiency of bacterial inactivation largely depends on the type of disinfectant applied. The disinfection efficiencies of hydrogen peroxide and gaseous- and aqueous-phase ozone are $0.93,0.28$, and $0.42 \log$ for spinach (Figure 8A), 3.24, 0.38, and $0.81 \log$ for green bean (Figure 8B), 4.22, 0.75, and $0.85 \mathrm{log}$ for asparagus (Figure 8C), 2.28, 1.04, and $2.44 \log$ for cucumber (Figure 8D), and 1.98, 1.00, and $1.65 \log$ for red pepper (Figure $\mathbf{8 E}$ ). Free chlorine was found to be the most effective disinfectant, achieving a bacterial inactivation efficiency of greater than $4 \mathrm{log}$ for all vegetables investigated at a concentration of $500 \pm 15 \mathrm{mg} / \mathrm{L}$ and a contact time of $30 \mathrm{~min}$.

The overall bacterial inactivation efficiencies and percentage decreases in biothiol levels of the four disinfectants, averaged over the five vegetables studied, are summarized in Figure 9. Results clearly show that the effectiveness of the four disinfectants on bacterial inactivation follows the order gaseous-phase 

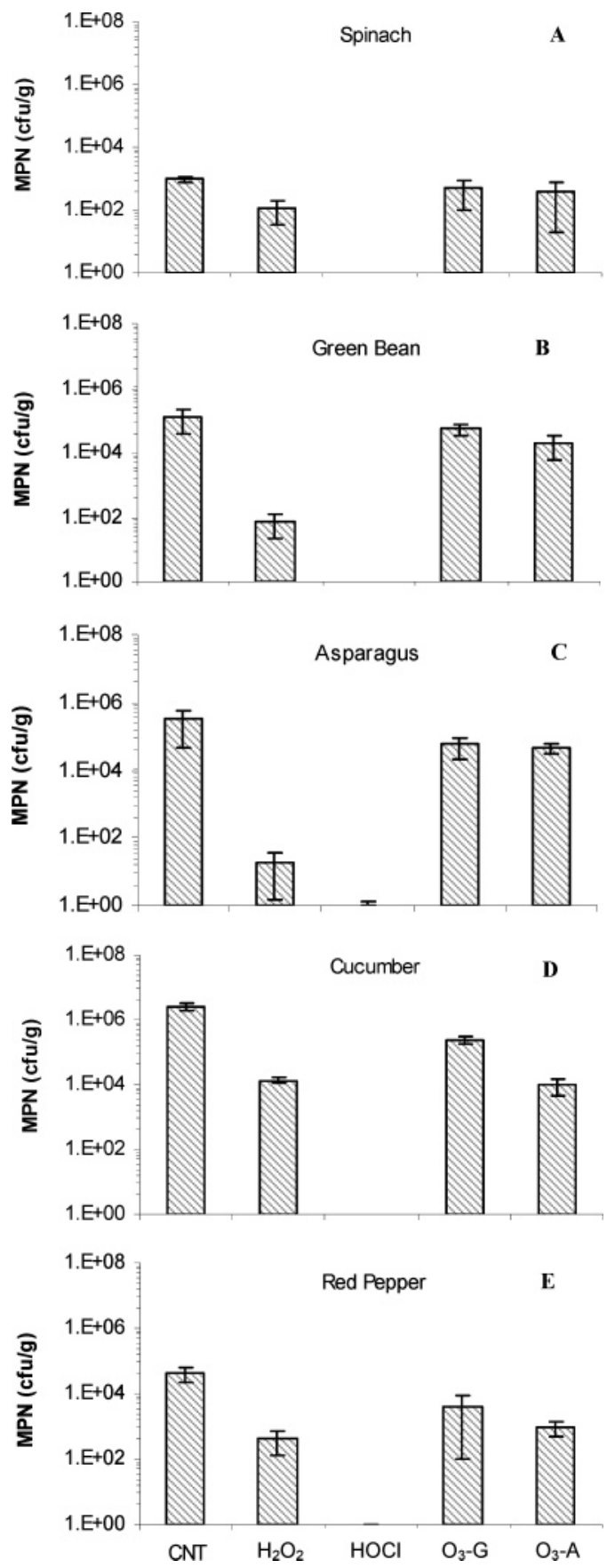

Figure 8. Impact of disinfectants on the inactivation of bacteria: $(\mathbf{A})$ spinach, (B) green bean, (C) asparagus, (D) cucumber, and (E) red pepper. Experimental conditions are the same as those for Figure 3. Error bars represent the standard deviation of duplicate samples.

ozone $<$ aqueous-phase ozone $<$ hydrogen peroxide $<$ free chlorine. On average, gaseous-phase ozone, aqueous-phase ozone, hydrogen peroxide, and free chlorine can inactivate about $74 \%, 86 \%, 97 \%$, and $100 \%$ of bacteria, respectively. Generally, a higher efficiency of bacterial inactivation is achieved in aqueous reactions than in gaseous reactions. In the aqueous phase, a portion of the bacteria can be washed off the vegetable surface into the oxidant solution, so disinfection occurs simultaneously on the vegetable surface and in solution. In the gaseous phase, disinfection only occurs on the vegetable surface. Results also show that there is no significant difference in biothiol loss among the four disinfectants. On average, hydrogen peroxide, free chlorine, and gaseous- and aqueous-phase ozone decreased

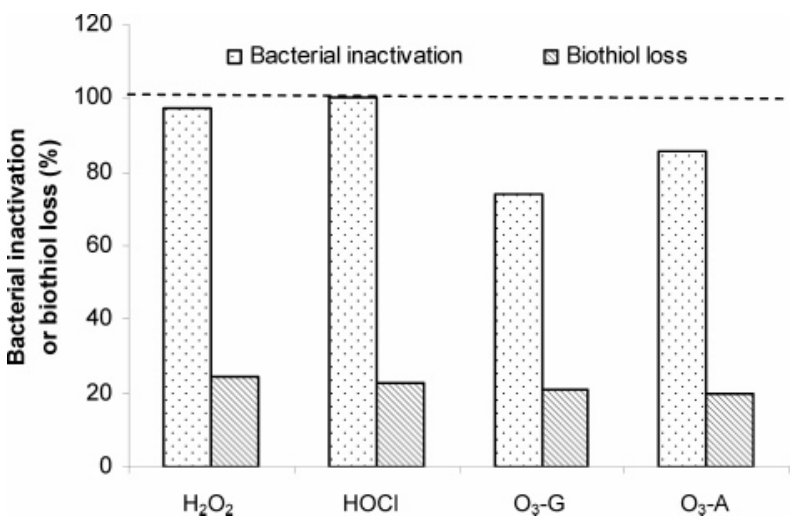

Figure 9. Overall bacterial inactivation efficiencies and percentage decreases in biothiol levels of the four disinfectants, averaged over the five vegetables studied. Experimental conditions are the same as those for Figure 3.

the mean level of all detected biothiols by $24 \%, 23 \%, 21 \%$, and $20 \%$, respectively.

\section{DISCUSSION}

The antioxidant GSH is essential for the cellular detoxification of reactive oxygen species (48). All five vegetables studied contain a significant amount of GSH. The level of GSH is usually much higher than the levels of other biothiols detected in the vegetables (except CYS in red pepper). After treatment with four disinfection technologies, the greatest decrease in mean GSH level was observed for spinach $(54-61 \%)$ and red pepper $(60-71 \%)$. However, the decrease in mean GSH level was less prominent for green bean $(0-11 \%)$, asparagus $(4-15 \%)$, and cucumber $(0-10 \%)$. This probably indicates that spinach and red pepper are more penetrable for interior GSH oxidation by the disinfectants than green bean, asparagus, and cucumber.

Oxidative stress plays an important role in the progression of neurodegenerative and age-related diseases, causing damage to proteins, DNA, and lipids (49). Changes in the intracellular GSH/GSSG ratio can also affect signaling pathways that participate in various physiological responses from cell proliferation to gene expression and apoptosis (50). Spinach contains the highest level of GSSG (91.8 nmol/g), and green bean contains $9.7 \mathrm{nmol} / \mathrm{g}$ GSSG. The GSSG level is relatively insignificant in asparagus, cucumber, and red pepper with baseline concentrations in the range of $0.3-1.3 \mathrm{nmol} / \mathrm{g}$. The GSSG content may either increase or decrease after disinfection, depending on the relative significances of GSH transformation and GSSG decomposition. An oxidative stress is most possibly developed in spinach (GSH/GSSG $=4.3$ in control samples) and least possibly developed in cucumber $(\mathrm{GSH} / \mathrm{GSSG}=274.1$ in control samples).

Among the five vegetables, asparagus contains most of the biothiols and is also very rich in GSH and NAC. The skin of asparagus protects interior biothiols against oxidative damage as well as the pod of green bean. On the contrary, the decrease in biothiol levels is more significant in spinach, cucumber, and red pepper with respect to certain types of biothiols. The greatest biothiol decrease was observed in spinach, which has the largest surface area per unit weight exposed to the disinfectants.

The results show that the potential decrease in biothiols during disinfection is dependent upon the biothiol type, the disinfectant, and the vegetable (and potentially other factors, e.g., temperature, $\mathrm{pH}$, etc.). For example, free chlorine and aqueous-phase ozone decreased the mean level of GGC by $20 \%$ and $25 \%$ in 
green bean, respectively, but hydrogen peroxide and gaseousphase ozone exerted no effect on GGC statistically.

The major goal of vegetable disinfection is to inactivate pathogenic microorganisms. The efficiency of pathogen inactivation usually depends on the type of disinfectant, contacting conditions (e.g., exposure time, disinfectant concentration, and $\mathrm{pH}$ ), and characteristics of vegetable surfaces. Typically the microbial population on vegetable or fruit surfaces is reduced by $90-99 \%$ (51). Among the four disinfection technologies investigated, free chlorine is most effective. The efficacy of chlorination on microbial inactivation is expected to improve if an acidic pH (e.g., pH 6) is used. In an acidic region, aqueous chlorine exists mainly in the form of $\mathrm{HOCl}$, which has a much stronger potential for bacterial inactivation than its conjugate (i.e., $\mathrm{OCl}^{-}$). Surfactants may also be used in combination with chlorine to enhance the efficiency of bacterial inactivation (52). Surfactants can reduce the surface tension of vegetables, enhancing the penetration of $\mathrm{HOCl}$ into vegetable contours and natural openings. Since free chlorine is very effective in bacterial inactivation, a lower concentration (e.g., $200 \mathrm{mg} / \mathrm{L}$ ) may be used to alleviate the stress on biothiol decrease but concurrently achieve sufficient bacterial disinfection.

Hydrogen peroxide is the second most effective disinfectant, but a concentration as high as 5\% (by weight) is required in comparison with much lower concentrations of other oxidants studied. Hydrogen peroxide is more expensive and also decomposes more quickly than free chlorine once used for vegetable processing. In our reaction system, approximately half of the hydrogen peroxide would decompose spontaneously within one week after treating the vegetables.

Ozone possesses a stronger oxidation potential than both free chlorine and hydrogen peroxide. The comparatively lower bacterial inactivation efficiency of ozone is attributed to its low concentration in either the gaseous or aqueous phase. In the aqueous phase, the steady-state concentration of dissolved ozone was measured to be $8.0 \pm 2.0 \mathrm{mg} / \mathrm{L}$ at $\mathrm{pH} 7.6$ in our reaction system. In the gaseous phase, the ozone concentration was maintained at $40 \mathrm{ppm}$. It should be noted that $1 \mathrm{ppm}(\mu \mathrm{L} / \mathrm{L})$ ozone in air contains only about $1 / 500$ th as many molecules of ozone as $1 \mathrm{ppm}(\mathrm{mg} / \mathrm{L})$ in water. The advantages of ozone as a food disinfectant lie in its high oxidation potential, decomposition to nontoxic oxygen, and easy applicability (e.g., common use of gaseous ozone for atmospheric control of food pathogens and fungi). Hydroxyl radicals may be generated by aqueous ozone at high $\mathrm{pH}$ as an effective alternative for food disinfection. Hydroxyl radical, possessing an oxidation potential higher than that of ozone, generally reacts with organic materials at a diffusion rate. It is thus hypothesized that a majority of hydroxyl radicals will be consumed on the vegetable surface for bacterial inactivation, whereas the oxidation of interior biothiols is minimized.

While this study was conducted only for a single oxidant dosage, it does demonstrate clearly that beneficial biothiols can be removed during food processing under certain disinfection conditions. More work is needed to determine the variability in removals achieved under varied oxidant dosages. Specifically, an ongoing study will investigate the kinetics of biothiol decrease during vegetable disinfection by the four disinfection technologies mainly on the basis of the concept of CT (oxidant concentration $\times$ contact time). It is anticipated that this work and our ongoing study will help to develop criteria or guidelines allowing sufficient disinfection on vegetables, concurrent with minimization of loss of biologically important antioxidants (i.e., biothiols).

\section{ACKNOWLEDGMENT}

We thank graduate students Min Chen, Rong Shi, and Tulin Otamis of the University of Missouri-Rolla (UMR) for their assistance in the bacteria and biothiol analysis.

\section{LITERATURE CITED}

(1) Ries, A. A.; Zaza, S.; Langkop, C.; Tauxe, R. V.; Blake, P. A. A multistate outbreak of Salmonella Chester linked to imported cantaloupe. Program and Abstracts of the $30^{\text {th }}$ Interscience Conference on Antimicrobial Agents and Chemotherapy; American Society for Microbiology: Washington, DC, 1990.

(2) Dewaal, C. S.; Alderton, L.; Jacobson, M. F. Outbreak alert! Closing the gaps in our federal food-safety net; Center for Science in the Public Interest: Washington, DC, 2000.

(3) Centers for Disease Control. Multistate outbreak of Salmonella serotype Poona infections associated with eating cantaloupe from Mexico, United States and Canada, 2000-2002; Morbidity and Mortality Weekly Report 51; Atlanta, GA, 2002; pp 10441047.

(4) Thomas, J. L.; Palumbo, M. S.; Farrar, J. A.; Farver, T. B.; Cliver, D. O. Industry practices and compliance with U.S. Food and Drug Administration guidelines among California sprout firms. J. Food Prot. 2003, 66 (7), 1253-1259.

(5) Kim, J. G.; Yousef, A. E.; Khadre, M. A. Ozone and its current and future application in the food industry. Adv. Food Nutr. Res. 2003, 45, 167-218.

(6) Graham, D. M. Use of ozone for food processing. Food Technol. 1997, 51 (6), 72-75.

(7) $\mathrm{Xu}, \mathrm{L}$. Use of ozone to improve the safety of fresh fruits and vegetables. Food Technol. 1999, 53 (10), 58-61.

(8) Kim, J. G.; Yousef, A. E.; Dave, S. Application of ozone for enhancing the microbiological safety and quality of foods: a review. J. Food Prot. 1999a, 62 (9), 1071-1087.

(9) Kim, J. G.; Yousef, A. E.; Chism, G. W. Use of ozone to inactivate microorganisms on lettuce. J. Food Saf. 1999b, 19, $17-34$.

(10) Zhao, J.; Cranston, P. M. Microbial decontamination of black pepper by ozone and the effect of the treatment on volatile oil constituents of the spice. J. Sci. Food Agric. 1995, 68 (1), 1118.

(11) Williams, R. C.; Sumner, S. S.; Golden, D. A. Survival of Escherichia coli O157:H7 and Salmonella in apple cider and orange juice as affected by ozone and treatment temperature. $J$. Food Prot. 2004, 67 (11), 2381-2386.

(12) Rodgers, S. L.; Cash, J. N.; Siddiq, M.; Ryser, E. T. A comparison of different chemical sanitizers for inactivating Escherichia coli O157:H7 and Listeria monocytogenes in solution and on apples, lettuce, strawberries, and cantaloupe. J. Food Prot. 2004, 67 (4), 721-731.

(13) Perez, A. G.; Sanz, C.; Rios, J. J.; Olias, R.; Olias, J. M. Effects of ozone treatment on postharvest strawberry quality. J. Agric. Food Chem. 1999, 47 (4), 1652-1656.

(14) Koseki, S.; Yoshida, K.; Isobe, S.; Itoh, K. Efficacy of acidic electrolyzed water for microbial decontamination of cucumbers and strawberries. J. Food Prot. 2004, 67 (6), 1247-1251.

(15) Fisher, C. W.; Lee, D.; Dodge, B. A.; Hamman, K. M.; Robbins, J. B.; Martin, S. E. Influence of catalase and superoxide dismutase on ozone inactivation of Listeria monocytogenes. Appl. Environ. Microbiol. 2000, 66 (4), 1405-1409.

(16) Castillo, A.; McKenzie, K. S.; Lucia, L. M.; Acuffi, G. R. Ozone treatment for reduction of Escherichia coli 0157:H7 and Salmonella serotype Typhimurium on beef carcass surfaces. $J$. Food Prot. 2003, 66 (5), 775-779.

(17) Novak, J. S.; Yuan, J. T. Viability of Clostridium perfringens, Escherichia coli, and Listeria monocytogenes surviving mild heat or aqueous ozone treatment on beef followed by heat, alkali, or salt stress. J. Food Prot. 2003, 66 (3), 382-389. 
(18) Beuchat, L. R. Surface decontamination of fruits and vegetables eaten raw: a review; World Health Organization, Food Safety Unit WHO/FSF/FOS/98.2: Geneva, Switzerland, 1998; http://www.who.int/foodsafety/publications/fs_management/en/ surface_decon.pdf.

(19) Tchobanoglous, G.; Burton, F. L. Wastewater Engineering: Treatment, Disposal, and Reuse, 3rd ed. (Metcalf \& Eddy, Inc.); McGraw-Hill: New York, 1991; p 333.

(20) Gonzalez, R. J.; Luo, Y.; Ruiz-Cruz, S.; McEvoy, J. L. Efficacy of sanitizers to inactivate Escherichia coli O157:H7 on freshcut carrot shreds under simulated process water conditions. $J$. Food Prot. 2004, 67 (11), 2375-2380.

(21) Pirovani, M. E.; Guemes, D. R.; Di Pentima, J. H.; Tessi, M. A. Survival of Salmonella hadar after washing disinfection of minimally processed spinach. Lett. Appl. Microbiol. 2000, 31 (2), 143-148.

(22) Yu, K.; Newman, M. C.; Archbold, D. D.; Hamilton-Kemp, T. R. Survival of Escherichia coli O157:H7 on strawberry fruit and reduction of the pathogen population by chemical agents. J. Food Prot. 2001, 64 (9), 1334-40.

(23) Lukasik, J.; Bradley, M. L.; Scott, T. M.; Dea, M.; Koo, A.; Hsu, W. Y.; Bartz, J. A.; Farrah, S. R. Reduction of poliovirus 1, bacteriophages, Salmonella montevideo, and Escherichia coli O157:H7 on strawberries by physical and disinfectant washes. J. Food Prot. 2003, 66 (2), 188-193.

(24) Escudero, M. E.; Velazquez, L.; Favier, G.; de Guzman, A. M. Effectiveness of chlorine, organic acids and UV treatments in reducing Escherichia coli O157:H7 and Yersinia enterocolitica on apples. Cent. Eur. J. Public Health 2003, 11 (2), 68-72.

(25) Parnell, T. L.; Harris, L. J.; Suslow, T. V. Reducing Salmonella on cantaloupes and honeydew melons using wash practices applicable to postharvest handling, foodservice, and consumer preparation. Int. J. Food Microbiol. 2005, 99 (1), 59-70.

(26) Bari, M. L.; Sabina, Y.; Isobe, S.; Uemura, T.; Isshiki, K. Effectiveness of electrolyzed acidic water in killing Escherichia coli O157:H7, Salmonella enteritidis, and Listeria monocytogenes on the surfaces of tomatoes. J. Food Prot. 2003, 66 (4), 542-548.

(27) Sinhamahapatra, M.; Biswas, S.; Das, A. K.; Bhattacharyya, D. Comparative study of different surface decontaminants on chicken quality. Br. Poult. Sci. 2004, 45 (5), 624-630.

(28) Shin, J. H.; Chang, S.; Kang, D. H. Application of antimicrobial ice for reduction of foodborne pathogens (Escherichia coli O157: H7, Salmonella Typhimurium, Listeria monocytogenes) on the surface of fish. J. Appl. Microbiol. 2004, 97 (5), 916-922.

(29) Fabrizio, K. A.; Sharma, R. R.; Demirci, A.; Cutter, C. N. Comparison of electrolyzed oxidizing water with various antimicrobial interventions to reduce Salmonella species on poultry. Poult. Sci. 2002, 81 (10), 1598-1605.

(30) Deza, M. A.; Araujo, M.; Garrido, M. J. Inactivation of Escherichia coli O157:H7, Salmonella enteritidis and Listeria monocytogenes on the surface of tomatoes by neutral electrolyzed water. Lett. Appl. Microbiol. 2003, 37 (6), 482-487.

(31) Juven, B. J.; Pierson, M. D. Antibacterial effects of hydrogen peroxide and methods for its detection and quantitation. J. Food Prot. 1996, 59 (11), 1233-1241.

(32) Parish, M. E.; Beuchat, L. R.; Suslow, T. V.; Harris, L. J.; Garrett, E. H.; Farber, J. N.; Busta, F. F. Methods to reduce/eliminate pathogens from fresh and fresh-cut produce. IFT/FDA Report on Task Order 3. Comprehensive Rev. Food Sci. Food Saf. 2003, 2 (Suppl.), 161-171.

(33) Gulati, B. R.; Allwood, P. B.; Hedberg, C. W.; Goyal, S. M. Efficacy of commonly used disinfectants for the inactivation of calicivirus on strawberry, lettuce, and a food-contact surface. $J$. Food Prot. 2001, 64 (9), 1430-1434.

(34) Allwood, P. B.; Malik, Y. S.; Hedberg, C. W.; Goyal, S. M. Effect of temperature and sanitizers on the survival of feline calicivirus, Escherichia coli, and F-specific coliphage MS2 on leafy salad vegetables. J. Food Prot. 2004, 67 (7), 14511456.
(35) Ukuku, D. O. Effect of hydrogen peroxide treatment on microbial quality and appearance of whole and fresh-cut melons contaminated with Salmonella spp. Int. J. Food Microbiol. 2004, 95 (2), 137-146.

(36) Sander, J. E.; Hofacre, C. L.; Cheng, I. H.; Wyatt, R. D. Investigation of resistance of bacteria from commercial poultry sources to commercial disinfectants. Avian Dis. 2002, 46 (4), 997-1000.

(37) Jones, D. P.; Coates, R. J.; Flagg, E. W.; Eley, J. W.; Block, G.; Greenberg, R. S.; Gunter E. W.; Jackson, B. Glutathione in foods listed in the National-Cancer-Institute's Health Habits and History Food Frequency Questionnaire. Nutr. Cancer 1992, 17 (1), 57-75.

(38) Miller, A. R. Oxidation of cell wall polysaccharides by hydrogen peroxide: a potential mechanism for cell wall breakdown in plants. Biochem. Biophys. Res. Commun. 1986, 141 (1), 238244.

(39) Finley, J. W.; Wheeler, E. L.; Witt, S. C. Oxidation of glutathione by hydrogen peroxide and other oxidizing agents. J. Agric. Food Chem. 1981, 29 (2), 404-407.

(40) Enshina, A. N.; Voitik, N. P. The effect of regular treatment with ozone on the chemical composition of potatoes and vegetables. Vopr. Pitan. (in Russian) 1989, 6, 61-64.

(41) Sen, C. K.; Packer, L. Thiol homeostasis and supplements in physical exercise. Am. J. Clin. Nutr. 2000, 72 (Suppl. 2), 653S669S.

(42) Wlodek, L. Beneficial and harmful effects of thiols. Pol. J. Pharmacol. 2002, 54 (3), 215-223.

(43) Demirkol, O.; Adams, C.; Ercal, N. Biologically important thiols in various vegetables and fruits. J. Agric. Food Chem. 2004, 52 (26), 8151-8154.

(44) Ishizaki, K.; Shinriki, N.; Matsuyama, H. Inactivation of Bacillus spores by gaseous ozone. J. Appl. Bacteriol. 1986, 60 (1), 6772.

(45) Standard Methods for the Examination of Water and Wastewater, 20th ed.; American Public Health Association: Washington, DC, 1998; method 4500-O 3 .

(46) Barlaz, M. A.; Schaefer, D. M.; Ham, R. K. Effects of prechilling and sequential washing on enumeration of microorganisms from refuse. Appl. Environ. Microb. 1989, 55, 50-54.

(47) Atlas, R. M.; Brown, A. E.; Dobra, K. W.; Miller, L. Experimental Microbiology-Fundamentals and Applications; Macmillan Publishing Co.: New York, 1984; pp 110-111.

(48) Dringen, R.; Hirrlinger, J. Glutathione pathways in the brain. Biol. Chem. 2003, 384 (4), 505-516.

(49) Grinberg, L.; Fibach, E.; Amer, J.; Atlas, D. N-acetylcysteine amide, a novel cell-permeating thiol, restores cellular glutathione and protects human red blood cells from oxidative stress. Free Radical Biol. Med. 2005, 38 (1), 136-145.

(50) Rahman, I.; Biswas, S. K.; Jimenez, L. A.; Torres, M.; Jay Forman, H. Glutathione, stress responses, and redox signaling in lung inflammation. Antioxid. Redox Signaling 2005, 7 (12), 42-59.

(51) Brackett, R. E. Microbiological spoilage and pathogens in minimally processed refrigerated fruits and vegetables. In Minimally Processed Refrigerated Fruits and Vegetables; Wiley, R. C., Ed.; Chapman and Hall: New York, 1994; pp 269312.

(52) Spotts, R. A.; Peters, B. B. Use of surfactants with chlorine to improve pear decay control. Plant Dis. 1982, 66 (8), 725727.

Received for review June 8, 2005. Revised manuscript received October 13, 2005. Accepted October 17, 2005. We acknowledge the Environmental Research Center for Emerging Contaminants of UMR and the John and Susan Mathes Professorship for partial support of this work.

JF051359F 